RESEARCH ARTICLE

\title{
Performance of atmospheric and topographic correction methods on Landsat imagery in mountain areas
}

\author{
Steven Vanonckelen ${ }^{1 *}$, Stefaan Lhermitte ${ }^{2}$, Vincent Balthazar ${ }^{3}$ and Anton Van \\ Rompaey $^{1}$ \\ ${ }^{1}$ Division of Geography, Katholieke Universiteit Leuven, Celestijnenlaan 200E, BE-3001 \\ Heverlee, Belgium (steven.vanonckelen@ees.kuleuven.be, : +32 16329763, \\ anton.vanrompaey@ees.kuleuven.be,+32 16326403) \\ ${ }^{2}$ Royal Netherlands Meteorological Institute, Wilhelminalaan 10, AE-3730 De Bilt, the \\ Netherlands (stef.lhermitte@knmi.nl, +31 30 2206366) \\ ${ }^{3}$ Earth and Life Institute, Université Catholique de Louvain, Place Louis Pasteur, BE-1348 \\ Louvain-La-Neuve, Belgium (vincent.balthazar@uclouvain.be, +32 10479182)
}

(Received $x x x ;$ accepted $x x x)$

\section{Acknowledgements}

The research was conducted for the project called "Remote sensing of the forest transition and its ecosystem impacts in mountain environments" (FOMO). The authors would like to thank Rudolf Richter and Daniel Schlaepfer for the help with this paper.

\section{Funding}

The work was supported by the Research Program for Earth Observation Stereo II of the Belgian Science Policy (BELSPO) [contract SR/00/133]. 


\title{
Performance of atmospheric and topographic correction methods on Landsat imagery in mountain areas
}

\begin{abstract}
An effective removal of atmospheric and topographic effects on remote sensing imagery is an essential preprocessing step to accurately map land cover in mountain areas. Various techniques that remove these effects have been proposed and consist of specific combinations of an atmospheric and a topographic correction method. However, a wide range of new combined correction methods are possible to generate by applying alternative combinations of atmospheric and topographic corrections. At present a systematic overview of the statistical performance and data input requirement of preprocessing techniques is missing. In this analysis, 15 permutations of two atmospheric and/or four topographic correction methods were compared along with uncorrected imagery in the Romanian Carpathian mountains. Furthermore, results of the integrated ATCOR3 method were included. Statistical results showed that combination of a transmittance based atmospheric correction and a pixel-based $\mathrm{C}$ or Minnaert topographic correction reduced the image distortions most efficiently in the study area. Overall results indicated that topographic correction had a larger impact than atmospheric correction and there was a trade-off between the statistical performance of preprocessing techniques and their data requirement.
\end{abstract}

Keywords: mountain areas; illumination; atmospheric correction; topographic correction; Landsat; integrated correction model. 


\section{Introduction}

Worldwide, mountain areas are experiencing rapid land cover changes that affect a set of ecosystem services, such as soil and water conservation, biodiversity preservation and carbon sequestration (DeFries et al., 2004; Foley et al., 2005; Lambin and Meyfroidt, 2010; World Health Organization, 2005). Not surprisingly, increasing efforts are invested in land cover monitoring and mapping of mountain areas. The relative inaccessibility of mountain areas favors remote sensing techniques as a monitoring tool (Lambin and Geist, 2006; Turner et al., 2007). Implementation of remote sensing tools is, however, often hampered by problems originating from atmospheric and topographic distortions (Singh et al., 2011). Therefore, preprocessing techniques are an essential step to improve interpretation of satellite imagery. Atmospheric correction (AC) methods aim at removing distortions caused by the interaction between radiance and atmosphere (e.g. molecular scattering and absorption by gases). The most popular AC method is the dark object subtraction method (Chavez, 1996). A list of more advanced radiative transference models is provided in Table 1. Some AC methods are based on transmittance functions: moderate spectral resolution atmospheric transmittance algorithm (Berk et al., 1998), the atmospheric part of the integrated radiometric correction method by Kobayashi and SangaNgoie (2008) and the atmospheric part of the ATCOR3 method (Richter, 1996; 1998). These last two atmospheric corrections are explained in the methodology section. Topographic correction (TC) aims at removing topographic distortions by deriving the radiance that would be observed in flat terrain. A list of topographic corrections is shown in Table 1. Three major types of TC methods have been developed. The simplest of these methods involve empirical normalizations, such as spectral band ratioing (Colby, 1991; Ono et al., 2007). Geometrical corrections assuming Lambertian reflection are considerably more sophisticated, such as cosine correction (Teillet et al., 1982). Most advanced geometrical corrections assume non-Lambertian behaviour, such as Minnaert corrections (Bishop and Colby, 2002; Lu et al., 2008; Minnaert, 1941; Smith et al., 1980), C-correction (Teillet et al., 1982) and sun-canopy-sensor correction.

During the past 30 years, AC and TC methods have mainly been evaluated individually, which is shown in Table 1. As tested by Schroeder et al. (2006) and Vicente-Serrano et al. (2008), the major distortions in Landsat bands 4 to 7 originated from differential illumination due to topography, since longer wavelengths were less susceptible to aerosol effects. The C-correction reduced differences between north- and south-facing slope reflectances of Landsat imagery, especially in bands 3 and 4 (Vicente-Serrano et al., 2008). So far, only a limited number of AC and TC combinations has been tested, which are shown in Table 1. For example, Huang et al. (2008) and Wen et al. (2009) combined the MODTRAN code with different TC's. Differences in spectral values were reduced for similar land cover types and spectral properties became more homogeneous for different illumination angles. A maximum of five individual AC and/or TC methods has been implemented and compared by Riaño et al. (2003) and Vicente-Serrano et al. (2008). The analysis of Riaño et al. in 2003 compared one AC and four TC's, while Vicente-Serrano et al. (2008) compared effects of two AC and two TC methods 


\section{S. Vanonckelen et al.}

in 2008. In principle, many more 'new' combined models can be built with individual AC and TC methods. Appropriate combined corrections are selected according to the study area, available data and implementation time. Furthermore, the influence of integrated AC and TC methods has been evaluated. Examples are the IRC method of Kobayashi and Sanga-Ngoie (2008) and the ATCOR3 method of Richter (1996; 1998). Kobayashi and Sanga-Ngoie showed in 2008 that an integrated correction resulted in nearly flat regression lines between $\cos \beta$ and corrected radiances. A major disadvantage of integrated corrections is the implementation of a specific AC and TC, as shown in Table 1. Existing preprocessing techniques are based on a specific combination of an atmospheric and a topographic correction. In order to select the most appropriate preprocessing steps, the performance of combined corrections should be evaluated based on different individual $\mathrm{AC}$ and $\mathrm{TC}$ components.

The added value of this study is the decomposition of integrated models in an AC and a TC component. The study is unique since most similar studies to date lack a thorough comparison between different AC and TC methods. This paper systematically evaluates the effects of all possible combinations of two AC and four TC methods, along with uncorrected imagery. Thereby, a variety of representative methods is selected based on their data input requirement and automation complexity. Since ATCOR3 is a popular integrated model, the evaluation of this model is also included in the analyses.

\section{(Table 1)}

\section{Study Area and Dataset}

The study area consists of a Landsat-5 Thematic Mapper image (path 183/row 28) located in the central-eastern Carpathian mountains in Romania (Figure 1). The study area covers $31,110 \mathrm{~km}^{2}$ and comprises parts of the eastern Carpathian mountains and the Transylvanian Plateau. Elevation ranges between 53 and 2,545 $\mathrm{m}$ with a mean elevation of $570 \mathrm{~m}$.

(Figure 1)

The area is characterized by a temperate mountain climate with an average yearly rainfall volume of about $635 \mathrm{~mm}$ and a mean annual temperature of about $11^{\circ} \mathrm{C}$ in central Transylvania. The ridges of the eastern Carpathians consist of crystalline schist, sedimentary and volcanic rock. The steep hillslopes are covered with mixed forests consisting of coniferous (e.g. Abies alba and Picea abies) and broadleaved trees (e.g. Betula pendula, Carpinus betulus and Fagus sylvatica) (Kuemmerle et al., 2008). Footslopes and plateaus are used for farming and cattle herding. Total population in the study area is estimated at 2,667,000 people, of which 277,000 live in Brasov and 175,500 in Bacau (NIS Romania, 2010). The majority of the population receives an income from farming practices.

The Landsat-5 image from 24 July 2009 was obtained from the archive of the United States Geological Survey. In this analysis, all corrections were performed on six non-thermal bands: three 
visible bands $(0.45-0.52 \mu \mathrm{m}, 0.52-0.60 \mu \mathrm{m}$ and $0.63-0.69 \mu \mathrm{m})$ and three infrared bands $(0.76-0.90$ $\mu \mathrm{m}, 1.55-1.75 \mu \mathrm{m}$ and $2.08-2.35 \mu \mathrm{m})$. The image was orthorectified with precision terrain correction level L1T by the United States Geological Survey and no cloud masking was performed, since cloud coverage in the study area was below $1 \%$. The solar elevation and azimuth angles were $57.8^{\circ}$ and $136.9^{\circ}$, respectively. The digital elevation model (DEM) was the space shuttle radar topography mission (SRTM) from CGIARCSI/NASA, which was co-registered with the Landsat image using automatic tie matching and considering both Landsat displacement and acquisition geometry (RMSE < 0.5; Leica Geosystems, 2006). The SRTM provided a high-quality DEM at resolution levels of 1 arc $\sec (30 \times 30 \mathrm{~m})$ in the U.S.A. or $3 \operatorname{arc} \sec (90 \times 90 \mathrm{~m})$ worldwide (Rabus et al., 2003). Although the ASTER GDEM from the METI/NASA was characterized by a worldwide 1 arc sec resolution, several analyses have indicated that the ASTER GDEM was more subject to artefacts such as stripes or cloud anomalies (Hirt et al., 2010; Van Ede, 2004). Therefore, the SRTM version 4.1 was resampled to a pixel size of $30 \times 30 \mathrm{~m}$ by means of a bicubic spline interpolation to match the resolution of the Landsat image.

\section{Methodology}

First, digital numbers of each spectral band were converted into at-sensor radiances $\left(L_{s, \lambda}\right)$ based on gain and offset values included in the metadata (Chander et al., 2009). Afterwards, path radiances $\left(L_{p, \lambda}\right)$ were not atmospherically corrected or corrected with one of the atmospheric corrections described below, and converted to at-surface reflectances with Equation (1) (Chander et al., 2009):

$$
\rho_{T, \lambda}=\frac{\pi L_{p, \lambda} d^{2}}{E S U N_{\lambda} \cos \theta_{s}}
$$

where: $\rho_{T, \lambda}=$ observed surface reflectance on an inclined surface (dimensionless or $\%$ ); $\lambda=$ band wavelength; $L_{p, \lambda}=$ path radiance $\left(\mathrm{W} / \mathrm{m}^{2} \mathrm{sr} \mu \mathrm{m}\right) ; d=$ earth-sun distance (astronomical units); $E S U N_{\lambda}=$ mean exo-atmospheric solar irradiance $\left(\mathrm{W} / \mathrm{m}^{2} \mu \mathrm{m}\right)$; and $\theta_{s}=$ solar zenith angle (degrees). Furthermore, the ATCOR3 method was applied, which integrates an atmospheric and a topographic correction. In a final step, the normalized reflectances of a horizontal surface $\left(\rho_{H, \lambda}\right)$ were calculated based on one of the four TC methods described below.

\subsection{Atmospheric corrections}

In this paper, a simplified AC, a transmittance based AC and no correction were compared on one Landsat scene. Table 2 provides the implemented equations of the $\mathrm{AC}$ methods. The first and simplified AC method is the DOS correction, which assumes that observed radiances from dark objects are a good assessment for atmospheric scattering and diffusion. Thereby, a uniform atmosphere across the image is assumed and DOS only considers the effect of scattering (Bruce and Hilbert, 2004). The path radiance was estimated by subtracting a minimum radiance value $\left(L_{\min }\right)$ from 
each pixel, as shown in Equation (2) of Table 2 (Song et al., 2001). The minimum value was calculated for each band as the $1^{\text {th }}$ percentile radiance value over the entire image and accounts for the atmospheric effect (Chavez, 1996).

(Table 2)

The second method is the TF atmospheric correction, which implements the atmospheric part of the IRC method of Kobayashi and Sanga-Ngoie (2008). This correction removes the effects of Rayleigh scattering and water-vapor absorption. TF correction extends the DOS method with a denominator containing normalized and band specific transmittance functions of water-vapor absorption and Rayleigh scattering, as shown in Equation (3) of Table 2. Transmittance functions were calculated for each wavelength and normalized per band. Here, a simplified approach was implemented, calculating the normalized transmittance function for each band based on the mean wavelength. The Rayleigh scattering transmittance function $\left(T_{r, \lambda}\right)$ was calculated with Equation (4) of Table 2, which is based on sea-level atmospheric pressure $\left(P_{0}\right.$; in mbar), ambient atmospheric pressure $(P$; in mbar $)$ and wavelength $(\lambda)$. The value of sea-level atmospheric pressure was assumed 1,013 mbar and ambient atmospheric pressure (995 mbar) was obtained from daily mean surface pressures in NASA's atmospheric Giovanni portal (2012). Relative air mass $M$ was calculated with Equation (5) in Table 2. This value was constant across the study area, since $M$ was only dependent on the solar zenith angle $\left(\theta_{s}\right)$. The water-vapor transmittance function $\left(T_{w, \lambda}\right)$ was calculated with Equation (6) in Table 2 based on the following parameters: precipitable water vapor $(W$; in $\mathrm{cm})$, relative air mass $(M)$ and watervapor absorption coefficients $\left(a_{w}\right)$ given as a function of wavelength (Bird and Riordan, 1986). The precipitable water vapor $(1.39 \mathrm{~cm})$ was obtained from the Aqua satellite in NASA's atmospheric Giovanni portal (2012) and based on the central point in the image at acquisition. Values of $\mathrm{W}$ and $\mathrm{P}$ were selected from the center of the image and were assumed constant across the study area. Therefore, central values were compared with values in the four corners of the image. The minima and maxima of these values were only varying 1 to $5 \%$ of the central value.

\subsection{Topographic corrections}

Four different topographic corrections were evaluated in this analysis. Table 3 provides the implemented equations of all TC methods. The first method, band ratioing, is based on the assumption that reflectance values vary proportionally in all bands. The observed reflectance on an inclined terrain $\left(\rho_{T, \lambda}\right)$ was obtained by calculating the arithmetic mean of observed reflectances over all spectral bands, as shown in Equation (7) of Table 3.

(Table 3)

The second method, cosine correction, assumes a uniform reflectance of incident solar energy in all directions ( $\mathrm{Lu}$ et al., 2008). The incident solar angle $\beta$ is the angle between the normal to the ground 
surface and the solar zenith direction (Civco, 1989). The cosine of the incident solar angle was calculated with Equation (11) and varies between -1 and +1 :

$$
\cos \beta=\cos \theta_{s} \cos \theta_{n}+\sin \theta_{s} \sin \theta_{n} \cos \left(\phi_{t}-\phi_{a}\right)
$$

where $\theta_{n}, \phi_{t}$ and $\phi_{a}$, are slope angle of the terrain, aspect angle of the terrain, and solar azimuth angle, respectively. This illumination parameter is the basis of the cosine correction formula, which is provided in Equation (8) of Table 3. The cosine correction only includes direct solar irradiance on the ground and ignores diffuse irradiance from the sky and adjacent terrain reflected irradiance (Teillet et al., 1982). The third implemented method is the pixel-based Minnaert correction (PBM), which accounts for non-Lambertian reflectance behavior by means of an empirical Minnaert constant k. A global k-value was assessed for the entire image with Equation (9) in Table 3, assuming a homogeneous anisotropic nature of reflectance over the study area (Colby and Keating, 1998; Gitas and Devereux, 2006). More sophisticated approaches assessed wavelength-dependent k-values (Bishop and Colby, 2002; Bishop et al., 2003; Lu et al., 2008). The fourth implemented method, pixelbased C-correction (PBC), consisted of the topographic part of the integrated radiometric correction applied in the analysis of Kobayashi and Sanga-Ngoie in 2008. The PBC method adds an additional factor $C_{\lambda}$ to the cosine correction in Equation (10) of Table 3 to account for diffuse sky irradiance. The factor $C_{\lambda}$ is the quotient of the intercept $\left(b_{\lambda}\right)$ and the slope $\left(m_{\lambda}\right)$ of the regression line. This additional factor is function of terrain slope, solar zenith angle, topographic parameters derived from the SRTM ( $\beta$ and $h$-factor) and empirical parameters derived from the regression line between reflectance and cos $\beta\left(C_{\lambda}\right.$ and $h_{0}$-factor).

\subsection{Integrated ATCOR3 correction}

The ATCOR 3 correction integrates a MODTRAN atmospheric radiative transfer code and a modified Minnaert topographic method. This correction is similar to the combination of TF with PBM correction, although the atmospheric part of ATCOR3 implements MODTRAN and the $\mathrm{k}$ value is calculated differently. For reasons of comparison and visualisation, ATCOR3 results are shown in parentheses within the TF and PBM combination in all tables. The atmospheric part consists of an interactive and an automatic part (Richter, 1996). In the interactive part, sensor type and relevant acquisition information were chosen, such as solar zenith angle, calibration information and date. Secondly, a reference target (dense dark vegetation or water) was defined. The automatic phase calculated the visibility of the reference areas for the selected atmospheric characteristics and linked these characteristics with results obtained from the MODTRAN atmospheric radiative transfer code (Balthazar et al., 2012). Preset ATCOR look-up tables were implemented to calculate the radiation components, as well as molecular and particulate absorption and scattering (Frey and Parlow, 2009). The topographic ATCOR3 part is a modified Minnaert model based on a set of empirical rules (Richter et al., 2009). The normalized reflectance $\rho_{H, \lambda}$ is calculated with the correction factor (cos 
$\left.\beta / \cos \beta_{T}\right)^{\mathrm{b}}$ in equation (12), where $\mathrm{b}$ is function of wavelength and vegetation cover, and $\beta_{T}$ is a threshold value depending on $\theta_{s}$ :

$$
\rho_{H, \lambda}=\rho_{T, \lambda}\left(\frac{\cos \beta}{\cos \beta_{T}}\right)^{b}
$$

with $b=1 / 2$ for non-vegetation; $b=3 / 4$ for vegetation in the visible spectrum $(\lambda<720 \mathrm{~nm}$ ); and $b=$ $1 / 3$ for vegetation if $\lambda \geq 720 \mathrm{~nm}$. The ATCOR3 method combines two empirical parameters to calculate the BRDF model: a lower boundary threshold of the correction factor and a threshold angle $\beta_{T}\left(0-90^{\circ}\right)$. The first parameter regulates the intensity of the correction by adapting the correction factor. If the correction factor is smaller than 0.25 , it will be reset to 0.25 to prevent a too strong reduction (Richter and Schläpfer, 2011). The second parameter is the threshold value of the incident solar angle, below which the Lambertian correction is applied. Above this threshold, the correction factor is applied to correct $\rho_{T, \lambda}$. This threshold was calculated based on $\theta_{s}$ plus an increment that depends on its initial value, as described in Equations (13) to (15) (Richter et al., 2009):

$$
\begin{gathered}
\beta_{T}=\theta_{s}+20^{\circ} \text { if } \theta_{s} \leq 45^{\circ} \\
\beta_{T}=\theta_{s}+15^{\circ} \text { if } 45^{\circ}<\theta_{s}<55^{\circ} \\
\beta_{T}=\theta_{s}+10^{\circ} \text { if } \theta_{s} \geq 55^{\circ}
\end{gathered}
$$

\subsection{Evaluation of combined corrections}

The combined correction methods were evaluated based on three analyses that test the homogeneity of reflectance values within a given land cover class or within the entire image. Since forest was the dominant land cover class, most statistical analyses were carried out on a set of 4,000 forest pixels. These pixels were delineated on the basis of ground control points collected during field visits in May 2010 and July 2011 and visual interpretation of high-resolution satellite imagery (WorldView-2, 8 bands, $46 \mathrm{~cm}$ resolution, acquisition date 13 October 2010). Forest pixels were classified in two groups, based on visual inspection of the satellite data and the value of $\cos \beta$ : illuminated $(\cos \beta>0.8)$ and shaded forest pixels ( $\cos \beta<0.6)$. Visual inspection was performed by comparing the illuminated (sun-oriented) and shaded land units on true color composites before and after correction.

The combined correction methods were evaluated based on the following three analyses:

(1) By comparing differences in reflectance values between shaded and illuminated slope groups, whereby each group was represented by 2,000 forest pixels. These differences are expected to decrease after successful correction. Furthermore, the reflectance values between all pairs of shaded and illuminated slope groups before and after correction were tested with a dependent $t$-test for paired samples. Equation (16) was implemented where $\bar{z}$ is difference in average reflectance values for shaded and illuminated slope groups, $s$ is the sample standard deviation and $n$ is the sample size (i.e. the 15 combined corrections and ATCOR3). The $t$-test was performed at the significance level 0.05 . 


$$
t=\frac{\bar{z}}{s} \sqrt{n}
$$

(2) By calculating the coefficient of variation (CV) of reflectance values within the selected forest pixels with Equation (17). The CV is expected to decrease after a successful combined correction.

$$
\mathrm{CV}=100 \frac{\mathrm{SD}}{\text { mean }}
$$

where SD is the standard deviation of the reflectance values within the forest class. To allow for a better interpretation, average $\mathrm{CV}$ values over all bands and $\mathrm{CV}_{\text {difference }}$ values were calculated $\left(\mathrm{CV}_{\text {difference }}=\mathrm{CV}_{\text {before correction }}-\mathrm{CV}_{\text {after correction }}\right)$.

(3) By examining the correlation between reflectance values and $\cos \beta$ before and after correction on a stratified sample of 5,000 points over the entire image and on the selected forest pixels. This statistic was evaluated based on the regression slope and the P-value for testing the hypothesis of no correlation before and after correction. The correlation is expected to decrease after a successful correction and correlations are significant if P-values are less than the significance level 0.05.

\section{Results}

All analyses were performed on the 15 combined methods and ATCOR3. The tables show results for all combinations. In contrast, it was impractical to show all combinations in the figures. Therefore, six representative combinations were presented: (a) no AC and no TC; (b) DOS without TC; (c) DOS with band ratio; (d) TF with cosine; (e) TF with PBM; and (f) TF with PBC. These six combinations were selected, since all single AC and TC methods were included and represented the range of modeling complexity. Furthermore, these combinations represented the minimum, intermediate and maximum results, and ATCOR3 results were similar to TF with PBM results.

\subsection{Differences in reflectances (shaded versus illuminated)}

Figure 2 shows reflectance values on illuminated (squares) and shaded slopes (circles) of the six bands and representative combinations for the selected forest pixels. In bands 1 to 3 of Figure 2a, small differences were present between average uncorrected reflectance values of illuminated and shaded areas. In contrast, average reflectance values were less homogenous in bands 4, 5 and 7. Combination of DOS without TC diminished differences between reflectance values of shaded and illuminated slopes (Figure 2b). Similar outputs were obtained for TF without TC. Application of DOS with band ratio overcorrected average reflectance values of visual bands and the difference in average reflectance values was reduced in bands 4 to 7 (Figure 2c). After cosine with TF correction (Figure 2d), average reflectance values of shaded slopes were higher than illuminated slopes for bands 1 to 3, which indicated an overcompensation of reflectance values of shaded slopes. ATCOR3 and the TF with PBM combination showed a reduction of differences between average illuminated and shaded reflectances 
in all bands (Figure 2e). Implementation of TF with PBC correction performed best (Figure 2f), since average reflectance values of illuminated and shaded areas were similar.

(Figure 2)

The largest differences in reflectance values between illuminated and shaded forest slopes were observed in band 4. Table 4 shows that topographic corrections had a stronger impact on the reflectance values than atmospheric correction in this band. Differences after TC without AC ranged between $-1.91 \%$ and $5.56 \%$, while differences after only AC ranged between $8.54 \%$ and $9.86 \%$. Furthermore, combination of AC and TC methods resulted in the smallest differences with a minimum of $-0.83 \%$ (TF with PBC) and a maximum of $5.83 \%$ (TF with band ratio). Results of the TF with PBM method (4.14\%) were comparable to the results of ATCOR3 (3.73\%). The smallest differences were found after TF with PBC correction (-0.83\%). When the $t$-test was significant, an asterisk was added in Table 4. Significant results were present for the ATCOR3 method and for combined corrections with a PBM or a PBC topographic correction. The PBM methods was only significant in combination with the transmittance based atmospheric correction. In contrast, the PBC correction was significant in combination with all atmospheric corrections.

(Table 4)

\subsection{Coefficient of variation}

Table 5 shows CV values for the selected forest pixels of each spectral band. Furthermore, average CV and $\mathrm{CV}_{\text {difference }}$ values over all bands are presented. There was only an increase in $\mathrm{CV}$ for bands 2,3 and 5 after band ratio without AC. All other combined corrections decreased the CV values. Results after TC without $\mathrm{AC}$ emphasized the effectiveness of topographic corrections. The $\mathrm{CV}_{\text {difference }}$ value after implementation of band ratio without $\mathrm{AC}$ was low (1.09). Furthermore, $\mathrm{CV}_{\text {difference }}$ values increased after implementation of the three other TC's without AC. The $\mathrm{CV}_{\text {difference }}$ value was highest for PBC (5.57), followed by PBM (4.65), and cosine (2.57), respectively. Table 5 also shows the performance of the two AC methods without TC. TF correction resulted in higher homogeneity than DOS correction, since the $\mathrm{CV}_{\text {difference }}$ value after $\mathrm{TF}$ (1.85) was higher than the value after DOS (1.04). Best results were obtained after combined corrections. Combination of TF with PBC correction resulted in the highest homogeneity $\left(\mathrm{CV}_{\text {difference }}\right.$ of 8.60$)$, closely followed by ATCOR3 $\left(\mathrm{CV}_{\text {difference }}\right.$ of 8.48) and TF with PBM correction $\left(\mathrm{CV}_{\text {difference }}\right.$ of 8.17).

\section{(Table 5)}

\subsection{Correlation analysis}

Correlation between $\cos \beta$ and reflectance values before and after correction was performed on the selected forest pixels and the stratified sampling over the entire image. Tables 6 and 7 show results of 
both sampling strategies for all combined corrections in band 4 . This band was selected based on the large differences in average reflectance values between illuminated and shaded slopes in the first statistical analysis. Before correction, correlation between $\cos \beta$ and reflectance values of both sampling strategies was positive. This is shown in Tables 6 and 7 by slope values of 16.3 and 14.6 respectively, and significance levels less than 0.05 . The dependency of reflectance values on terrain illumination was reduced after correction. All tested corrections decreased slope values of the regression line, although correlations remained significant for some combinations. After combining DOS without TC, positive correlation was still present. Slope values had decreased from 16.3 to 13.9 and from 14.6 to 12.6 , respectively. A significant correlation was still present for both samplings after combination of an AC with band ratio or cosine correction. In Tables 6 and 7, P-values were lower than the significance level and slope values were negative. Implementation of DOS with band ratio and TF with cosine presented negative slope values in both tables. Combination of PBM or PBC without an AC resulted in a small dependency, with slope values smaller than 3.0 and P-values between 0.31 and 0.39 . Dependency of reflectance values on terrain illumination was reduced after implementation of an AC with PBM or PBC method. For the forest pixels (Table 6), slope values ranged between 2.2 and 2.5, and $\mathrm{P}$-values indicated that data were uncorrelated $(\mathrm{P}>0.05)$. Table 7 shows that sampling over the entire image was even performing better than the forest sample, with slope values approximating 0 and P-values larger than 0.05. Results were improved most after ATCOR3 and combination of TF with PBM and PBC correction. Reflectance values and $\cos \beta$ were uncorrelated with reduced slope values of $1.1,1.3$, and 0.7 , respectively.

(Table 6)

(Table 7)

Figure 3 shows true color composite images before and after implementation of the six representative combined corrections. These images provide a better understanding of the study area and depict the removal of shading effects after combined correction. The image shows a $120 \mathrm{~km}^{2}$ representative zoom of the study area as indicated in Figure 1. Without any corrections applied, there are clear differences between sun-oriented and opposite slopes in Figure 3a. The output after DOS without a TC did not result in visual differences in Figure 3b. A comparable output was obtained for TF without TC. In contrast, combined AC and TC methods changed the appearance of the images. Band ratioing resulted in an overall lowering of reflectance values as expected after implementation of Equation (7) (Figure 3c). Combined TF and cosine correction resulted in a reduction of shades on poorly illuminated areas in Figure 3d, although an overcorrection in the visible bands appeared. Best results were obtained after combination of TF with $\mathrm{PBM}$ or PBC correction in Figures $3 \mathrm{e}$ and f. Differential illumination effects were reduced and spectral characteristics of sun-oriented and opposite slopes were similar.

(Figure 3) 


\section{S. Vanonckelen et al.}

\section{Discussion}

This analysis provided new insights for fifteen permutations of two atmospheric and/or four topographic corrections along with uncorrected imagery. Generally, visible bands presented small differences between average reflectance values of illuminated and shaded areas. These differences were produced by larger atmospheric than topographic distortions in bands 1 to 3 due to scattering and diffusion, and confirmed by results of previous research (Kobayashi and Sanga-Ngoie, 2008; Schroeder et al., 2006; Vicente-Serrano et al., 2008). Implementation of TF with cosine indicated an overcorrection of reflectance values of shaded slopes. The overcorrection of areas under low illumination conditions - especially steep terrain where incident angles approach $90^{\circ}$ - has been found in several analyses (Hantson and Chuvieco, 2011; Meyer et al., 1993; Teillet et al., 1982). ATCOR3 and combination of TF with PBM and PBC showed a reduction of differences between average reflectance values in all bands and significant $t$-test results. These results were comparable to experiments conducted by Huang et al. In 2008, Wen et al. in 2009 and Vicente-Serrano et al. in 2008. In our analysis, average $\mathrm{CV}_{\text {difference }}$ values increased after implementation of advanced TC's without AC. The average $\mathrm{CV}_{\text {difference }}$ value was highest for PBC, followed by $\mathrm{PBM}$ and cosine. Correlation analysis showed that PBM or PBC without an AC resulted in a small dependency. However, this dependency was even reduced after combined correction. This proved that TC methods had a larger impact on the results than AC methods. Valid explanations were the application of only one Landsat footprint and the mountainous terrain. Dependency between $\cos \beta$ and reflectance values was decreased most after ATCOR3 and the combination of TF with PBM or PBC. Similar results were obtained in a previous analysis by Kobayashi and Sanga-Ngoie in 2008. Largest illumination effects were observed in the forest class, which explained an improved performance of sampling over the entire Landsat image.

Considering overall results, this analysis showed that most complex combined corrections were most accurate but also most difficult to automate. Furthermore, the added value of complex TC methods was high, while the added value of AC methods was limited. These results confirmed findings of previous analyses by Eiumnoh and Shrestha in 2000 and Hale and Rock in 2003, where topographic effects had a larger impact on remote sensing data than atmospheric effects. Therefore, application of a combined correction based on a complex TC component and a rather straightforward AC component was justified in this case study.

\section{Conclusions}

In this analysis, the performance of the combination of three atmospheric and five topographic corrections and the integrated ATCOR3 method was evaluated along with uncorrected Landsat imagery. Most similar studies to date missed a thorough comparison between different AC and TC 
methods, while this analysis decomposed integrated models in an AC and a TC component and systematically evaluated effects of all combinations. Statistical comparison of illuminated versus shaded reflectance values without any correction indicated that major differences were present in bands 4 to 7. After implementation of combined corrections, these differences were reduced. The smallest differences in reflectance values were present after ATCOR3 correction or combination of an atmospheric correction with PBM or PBC. Furthermore, most of these combined corrections resulted in significant $t$-test results. Comparable conclusions were drawn from the analysis of the coefficients of variation for the forest sampling. The $\mathrm{CV}$ of each spectral band decreased after combined correction. Overall results indicated that TC had a larger impact on the reflectance values than AC. Added value of AC methods was relatively low, since only one Landsat image was implemented. Results of the AC methods were included since these methods are essential in time series analyses. In this study, ATCOR3 and combinations of TF with PBM or PBC performed best, although these methods required the largest amount of input data.

The added value of this study was the decomposition of integrated models and the systematic evaluation along with uncorrected imagery. This case study proved that the benefits in reduction of atmospheric and topographic distortions justified automation of more complex corrections in mountain areas. 


\section{References}

Balthazar, V., Vanacker V. and Lambin, E., 2012, Evaluation and parameterization of ATCOR3 topographic correction method for forest cover mapping in mountain areas. International Journal of Applied Earth Observation and Geoinformation, 18, pp. 436-450.

Berk, A, Bernstein, L.S., Anderson, G.P. , Robertson, D.C., Chetwynd, J.H. and Adler-Golden, S.M., 1998, MODTRAN Cloud and multiple scattering upgrades with application to AVIRIS. Remote Sensing of Environment, 65, pp. 367-375.

Bird, R.E. and Riordan, C., 1986, Simple solar spectral model for direct and diffuse irradiance on horizontal and tilted planes at the earth's surface for cloudless atmospheres. Journal of Climate and Applied Meteorology, 25, pp. 87-97.

Bishop, M.P. and Colby, J.D., 2002, Anisotropic reflectance correction of SPOT-3 HRV imagery. International Journal of Remote Sensing, 23, pp. 2125-2131.

Bishop, M.P., Shroder, J.F. and Colby, J.D, 2003, Remote sensing and geomorphometry for studying relief production in high mountains. Geomorphology, 55, pp. 345-361.

Blesius, L. and Weirich, F., 2005, The use of the Minnaert correction for land-cover classification in mountainous terrain. International Journal of Remote Sensing, 26, pp. 3831-3851.

Bruce, C.M. and Hilbert, D.W., 2004, Pre-processing methodology for application to Landsat TM/ETM+ imagery of the wet Tropics. Research report, Cooperative research centre for tropical rainforest ecology and management, Cairns, Australia. Accessed 13 July 2013. http://www.rrrc.org.au/rfcrc/downloads/44_landsat_preprocessing.pdf

Chander, G., Markham, B.L. and Helder, D.L., 2009, Summary of current radiometric calibration coefficients for Landsat MSS, TM, ETM and EO-1 ALI sensors. Remote Sensing of Environment, 113, pp. 893-903.

Chavez, P.S., 1996, Image-based atmospheric correction-revisited and improved. Photogrammetric Engineering and Remote Sensing, 62, pp. 1025-1036.

Civco, D.L., 1989, Topographic normalization of Landsat Thematic Mapper digital imagery. Photogrammetric Engineering and Remote Sensing, 55, pp. 1303-1309.

Colby, J.D., 1991, Topographic normalization in rugged terrain. Photogrammetric Engineering and Remote Sensing, 57, pp. 531-537.

Colby, J.D. and Keating, P.L., 1998, Land cover classification using Landsat TM imagery in the tropical highlands: the influence of anisotropic reflectance. International Journal of Remote Sensing, 19, pp. 1479-1500.

Conese, C., Gilabert, M.A., Maselli, F. and Bottai, L., 1993, Topographic normalization of TM scenes through the use of an atmospheric correction method and digital terrain models. Photogrammetric Engineering and Remote Sensing, 59, pp. 1745-1753.

Cuo, L., Vogler, J.B. and Fox, J.M., 2010, Topographic normalization for improving vegetation classification in a mountainous watershed in Northern Thailand. International Journal of Remote Sensing, 31, pp. 3037-3050.

DeFries, R.S., Foley, J.A. and Asner, G.P., 2004, Land-use choices: balancing human needs and ecosystem function. Frontiers in Ecology and the Environment, 2, pp. 249-257. 
Eiumnoh, A. and Shrestha, R. P., 2000, Application of DEM data to Landsat image classification: evaluation in tropical wet-dry climate. Photogrammetric Engineering and Remote Sensing, 66, pp. 297-304.

Ekstrand, S., 1996, Landsat TM-based forest damage assessment:correction for topographic effects. Photogrammetric Engineering and Remote Sensing, 62, pp. 151-161.

Frey, C. and Parlow, E., 2009, Geometry effect on the estimation of band reflectance in an urban area. Theoretical and Applied Climatology, 96, pp. 395-406.

Foley, J.A., DeFries, R., Asner, G.P., Barford, C., Bonan, G., Carpenter, S.R., Chapin, F.S., Coe, M.T., Daily, G.C., Gibbs, H.K., Helkowski, J.H., Holloway, T., Howard, E.A., Kucharik, C.J., Monfreda, C., Patz, J.A., Prentice, I.C., Ramankutty, N. and Snyder, P.K., 2005, Global consequences of land use. Science, 309, pp. 570-574.

Gao, Y. and Zhang, W., 2009, A simple empirical topographic correction method for ETM+ imagery. International Journal of Remote Sensing, 30, pp. 2259-2275.

Gilabert, M. A., Conese, C., and F. Maselli, 1994, An atmospheric correction method for the automatic retrieval of surface reflectances from TM images. International Journal of Remote Sensing, 15, pp. 2065-2086.

Giovanni portal, 2012, Interactive Visualization and Analysis. Goddard Earth Sciences, Data and Information Services Center, Washington, DC. Accessed July 162013. http://disc.sci.gsfc.nasa.gov/giovanni/overview/index.html

Gitas, I.Z., and B.J. Devereux, 2006, The role of topographic correction in mapping recently burned Mediterranean forest areas from Landsat TM images. International Journal of Remote Sensing, 27, pp. $41-54$.

Gu, D. and Gillespie, A., 1998, Topographic normalization of Landsat TM images of forest based on subpixel sun-canopy-sensor geometry. Remote Sensing of Environment, 64, pp. 166-175.

Hale, S.R. and Rock, B.N., 2003, Impact of topographic normalization on land-cover classification accuracy. Photogrammetric Engineering and Remote Sensing, 69, pp. 785-791.

Hantson, S. and Chuvieco, E., 2011, Evaluation of different topographic correction methods for Landsat imagery. International Journal of Applied Earth Observation and Geoinformation, 13, pp. 691-700.

Hirt, C., Filmer, M.S. and Featherstone, W.E., 2010, Comparison and validation of the recent freelyavailable ASTER GDEM ver1, SRTM ver4.1 and GEODATA DEM-9S ver3 digital elevation models over Australia. Australian Journal of Earth Sciences, 57, pp. 337-347.

Huang, H., Gong, P., Clinton, N. and Hui, F., 2008, Reduction of atmospheric and topographic effect on Landsat TM data for forest classification. International Journal of Remote Sensing, 29, pp. 56235642 .

Jensen, J.R., 1996, Introduction digital image processing: a remote sensing perspective. Prentice-Hall, Englewood Cliffs, New Jersey, 526 p.

Kneizys, F.X., Shettle, E.P., Abreu, L.W., Chetwynd, J.H., Anderson, G.P., Gallery, W.O., Selby, J.E.A. and Clough, S.A., 1988, User's Guide to LOWTRAN-7. Air Force Geophysics Laboratory, Hanscom, Massachusetts, $146 \mathrm{p}$. 
Kobayashi, S. and Sanga-Ngoie, K.,2008, The integrated radiometric correction of optical remote sensing imageries. International Journal of Remote Sensing, 29, pp. 5957-5985.

Kuemmerle, T., Muller, D., Griffiths, P. and Rusu, M., 2008, Land use change in Southern Romania after the collapse of socialism. Regional Environmental Change, 9, pp. 1-12.

Lambin, E.F. and Geist, H.J., 2006, Land use and land cover change, Local processes and global impacts. Springer-Verlag, Berlin, Heidelberg, pp. 236.

Lambin, E.F. and Meyfroidt, P., 2010, Land use transitions: socio-ecological feedback versus socioeconomic change. Land Use Policy, 27, pp. 108-118.

Leica Geosystems, 2006, Imagine AutoSync. White Paper, Leice Geosystems Geospatial Imaging, Norcross, Georgia, USA. Accessed: June 252013. http://geospatial.intergrapgh.com/products/ERDASIMAGINE/IMAGINEAutoSync/Details.aspx

Lenot, X., Achard, V. and Poutier, L., 2009, SIERRA: a new approach to atmospheric and topographic corrections for hyperspectral imagery. Remote Sensing of Environment, 113, pp. 1664-1677.

Liang, S. and Fang, H., 2004, An improved atmospheric correction algorithm for hyperspectral remotely sensed imagery. IEEE Geoscience and Remote Sensing Letters, 1, pp. 112-117.

Liang, S., Fang, H. and Chen, M., 2001, Atmospheric correction of Landsat ETM+ land surface imagery - part I, methods. IEEE Transactions on Geoscience and Remote Sensing, 39, pp. 2490-2498.

Lu, D., Ge, H., He, S., Xu, A., Zhou, G. and Du, H., 2008, Pixel-based Minnaert correction method for reducing topographic effects on a Landsat-7 ETM+ image. Photogrammetric Engineering and Remote Sensing, 74, pp. 1343-1350.

Meyer, P., Itten, K.L., Kellenberger, T., Sandmeier, S. and Sandmeier, R., 1993, Radiometric corrections of topographically induced effects on Landsat TM data in alpine environment. ISPRS Journal of Photogrammetry and Remote Sensing, 48, pp. 17-28.

Minnaert, N., 1941, The reciprocity principle in lunar photometry. Astrophysical Journal, 93, pp. 403410.

Mitri, G.H. and Gitas, I.Z., 2004, A performance evaluation of a burned area object-based classification model when applied to topographically and non-topographically corrected TM imagery. International Journal of Remote Sensing, 25, pp. 2863-2870.

Moran, M.S., Jackson, R.D., Slater, P.N. and Teillet, P.M., 1992, Evaluation of simplified procedures for retrieval of land surface reflectance factors from satellite sensor output. Remote Sensing of Environment, 41, pp. 169-184.

NIS Romania, 2010, Database of Localities. National Institute of Statistics, Bucharest, Romania.

Ono, A., Kajiwara, K. and Honda, Y., 2007, Development of vegetation index using radiant spectra normalized by their arithmetic mean. Proceedings $42^{\text {nd }}$ Conference of the Remote Sensing Society of Japan, 10-11 May 2007, Tokyo, Japan, pp. 99-100.

Rabus, B., Eineder, M., Roth, A. and Bamler, R., 2003, The shuttle radar topography mission - a new class of digital elevation models acquired by spaceborne radar. ISPRS Journal of Photogrammetry and Remote Sensing, 57, pp. 241-262. 
Rahman, H., and Dedieu, G., 1994, SMAC: a simplified method for the atmospheric correction of satellite measurements in the solar spectrum. International Journal of Remote Sensing, 15, pp. 123143.

Riaño, D., Chuvieco, E., Salas, F.J. and Aguado, I., 2003, Assessment of different topographic corrections in Landsat TM data for mapping vegetation types. IEEE Transactions on Geoscience and Remote Sensing, 41, pp. 1056-1061.

Richter, R., 1996, Atmospheric correction of satellite data with haze removal including a haze/clear transition region. Computers and Geosciences, 22, pp. 675-681.

Richter, R., 1997, Correction of atmospheric and topographic effects for high spatial resolution satellite imagery. International Journal of Remote Sensing, 18, pp. 1099-1111.

Richter, R., 1998, Correction of satellite imagery over mountainous terrain. Applied Optics, 37, pp. 4004-4015.

Richter, R., Kellenberger, T. and Kaufmann, H., 2009, Comparison of topographic correction methods. Remote Sensing, 1, pp. 184-196.

Richter, R. and Schlapfer, D., 2002, Geo-atmospheric processing of airborne imaging spectrometry data. Part 2. Atmospheric/topographic correction. International Journal of Remote Sensing, 23, pp. 2631-2649.

Richter, R. and Schläpfer, D., 2011, Atmospheric/topographic correction for satellite imagery. ATCOR 2/3 User Guide. Version 8.0.2.

Sandmeier, S. and Itten, K.I., 1997, A physically-based model to correct atmospheric and illumination effects in optical satellite data of rugged terrain. IEEE Transactions on Geoscience and Remote Sensing, 35, pp. 708-717.

Schroeder, T.A., Cohen, W.B., Song, C., Canty, M.J. and Yang, Z., 2006, Radiometric correction of multi-temporal Landsat data for characterization of early successional forest patterns in western Oregon. Remote Sensing of Environment, 103, pp. 16-26.

Singh, S., Sharma, J.K. and Mishra, V.D., 2011, Comparison of different topographic correction methods using AWiFS satellite data. International Journal of Advanced Engineering Sciences and Technologies, 7, pp. 103-109.

Smith, G.M. and Milton, E.J., 1999, The use of the empirical line method to calibrate remotely sensed data to reflectance. International Journal of Remote Sensing, 20, pp. 2653-2662.

Smith, J.A., Lin, T.L. and Ranson, K.J., 1980, The Lambertian assumption and Landsat data. Photogrammetric Engineering and Remote Sensing, 46, pp. 1183-1189.

Soenen, S.A., D.R. Peddle, C.A. Coburn, R.J. Hall, and F.G. Hall, 2008, Improved topographic correction of forest image data using a 3-D canopy reflectance model in multiple forward mode. International Journal of Remote Sensing, 29, pp. 1007-1027.

Singh, S., Sharma, J.K. and Mishra, V.D., 2011, Comparison of different topographic correction methods using AWiFS satellite data. International Journal of Advanced Engineering Sciences and Technologies, 7, pp. 103-109. 


\section{S. Vanonckelen et al.}

Song, C, Woodcock, C.E., Seto, K.C., Lenney, M.P. and Macomber, S.A., 2001, Classification and change detection using Landsat TM data: when and how to correct atmospheric effects. Remote Sensing of Environment, 75, pp. 230-244.

Sriwongsitanon, N., Surakit, K. and Thianpopirug, S., 2011, Influence of atmospheric correction and number of sampling points on the accuracy of water clarity assessment using remote sensing application. Journal of Hydrology, 401, pp. 203-220.

Teillet, P.M., Guindon, B. and Goodenough, D.G., 1982, On the slope-aspect correction of multispectral scanner data. Canadian Journal of Remote Sensing, 8, pp. 84-106.

Turner, B.L., Lambin, E.F. and Reenberg, A., 2007, The emergence of land change science for global environmental change and sustainability. Proceedings of the National Academy of Sciences of the United States of America, 104, pp. 20666-20671.

Van Ede, R., 2004, Destriping and geometric correction of an ASTER Level 1A Image. Master thesis, Utrecht University, Utrecht, the Netherlands, 36 p.

Veraverbeke, S., Lhermitte, S., Verstraeten, W.W and Goossens, R., 2011, A time integrated MODIS burn severity assessment using the multi-temporal differenced Normalized Burn Ratio (dNBRMT). International Journal of Applied Earth Observation and Geoinformation, 13, pp. 52-58.

Vermote, E. F., El Saleous, N. Z., Justice, C. O., Kaufman, Y. J., Privette, J., Remer, L., Roger, J. C. and Tanré, D., 1997, Atmospheric correction of visible to middle infrared EOS-MODIS data over land surface, background, operational algorithm and validation. Journal of Geophysical Research, 102, pp. 17131-17141.

Vicente-Serrano, S.M., Pérez-Cabello, F. and Lasanta, T., 2008, Assessment of radiometric correction techniques in analyzing vegetation variability and change using time series of Landsat images. Remote Sensing of Environment, 112, pp. 3916-3934.

Vincini, M. and Frazzi, E., 2003, Multitemporal evaluation of topographic normalization methods on deciduous forest TM data. IEEE Transactions on Geoscience and Remote Sensing, 41, pp. 2586-2590.

Wen, J., Liu, Q., Liu, Q., Xiao, Q. and Li, X., 2009, Parametrized BRDF for atmospheric and topographic correction and albedo estimation in Jiangxi rugged terrain, China. International Journal of Remote Sensing, 30, pp. 2875-2896.

World Health Organization, 2005, Ecosystems and human well-being, health synthesis, Millennium Ecosystem Assessment. WHO Press, Geneva, Switzerland, pp.64.

Wu, J., Bauer, M.E., Wang, D. and Manson, S., 2008, A comparison of illumination geometry-based methods for topographic correction of QuickBird images of an undulant area. ISPRS Journal of Photogrammetry and Remote Sensing, 63, pp. 223-236.

Zhang, W. and Gao, Y., 2011, Topographic correction algorithm for remotely sensed data accounting for indirect irradiance. International Journal of Remote Sensing, 32, pp. 1807-1824.

Zhang, Z., De Wulf, R.R., Van Coillie, F.M.B., Verbeke, L.P.C., De Clercq, E.M. and Ou, X., 2011, Influence of different topographic correction strategies on mountain vegetation classification accuracy in the Lancang Watershed, China. Journal of applied Remote Sensing, 5, pp. 1-21.

Zhao, W., Tamura, M. and Takahashi, H., 2000, Atmospheric and spectral corrections for estimating surface albedo from satellite data using 6S code. Remote Sensing of Environment, 76, pp. 202-212. 
International Journal of Remote Sensing

Table 1. Type, correction, reference and acronym of AC, TC and integrated (int.) or combined (comb.) methods.

\begin{tabular}{|c|c|c|c|}
\hline Type & Correction & Reference & Acronym \\
\hline \multirow[t]{12}{*}{$\mathrm{AC}$} & LOWTRAN-7 & Kneizys et al., 1988 & Low resolution atmospheric transmission \\
\hline & RTC's, image-based procedures and DOS & Moran et al., 1992 & Radiative transfer codes \\
\hline & Inverse technique & Gilabert et al., 1994 & \\
\hline & DOS & Chavez, 1996 & Dark object subtraction method \\
\hline & ATCOR2 & Richter, 1996 & An acronym for atmospheric correction \\
\hline & SMAC & Rahman and Dedieu, 1994 & Simplified method for AC \\
\hline & $6 \mathrm{~S}$ & $\begin{array}{l}\text { Sriwongsitanon et al., 2011; Vermote et al., } \\
\text { 1997; Zhao et al., 2000; }\end{array}$ & $\mathrm{S}$ econd simulation of a satellite signal in the solar spectrum \\
\hline & MODTRAN & Berk et al., 1998 & Moderate resolution atmospheric transmission \\
\hline & Empirical line & Smith and Milton, 1999 & \\
\hline & AC with look-up tables & Liang et al., 2001; Liang and Fang, 2004 & \\
\hline & DDV, MDDV and PARA & Song. et al., 2001 & Dense dark vegetation, modified DDV and path radiance approach \\
\hline & Transmittance functions (TF) & Kobayashi and Sanga-Ngoie, 2008 & This method is the AC part of the integrated radiometric correction \\
\hline \multirow[t]{21}{*}{ TC } & Minnaert & Bishop and Colby, 2002; Lu et al., 2008; & \\
\hline & Band ratios & Minnaert, 1941; Smith et al., 1980 & \\
\hline & & Colby, 1991; Ono et al., 2007 & \\
\hline & Cosine & Teillet et al., 1982 & \\
\hline & $\mathrm{C}$ & $\begin{array}{l}\text { Bishop et al., 2003; Jensen, 1996; Meyer et al., } \\
\text { 1993; Teillet et al., } 1982\end{array}$ & \\
\hline & Two stage topographic normalization & Civco, 1989 & \\
\hline & Minnaert with changing constant and correction based on empirical function & Ekstrand, 1996 & \\
\hline & & Gu and Gillespie, 1998 & Sun-canopy-sensor topographic correction \\
\hline & Band ratio, Minnaert, aspect partitioning and combinations of these corrections & Hale and Rock, 2003 & \\
\hline & C-Huang Wei & Huang et al., 2008 & \\
\hline & $\mathrm{PBC}$ and $\mathrm{PBM}$ & Kobayashi and Sanga-Ngoie, 2008 & Pixel-based Minnaert and pixel-based C-correction \\
\hline & Empirical line, cosine, C, Minnaert, statistical-empirical, SCS, b, SCS+C and & Soenen et al., 2008 & MFM-TOPO is canopy reflectance model-based TC \\
\hline & $\begin{array}{l}\text { MFM-TOPO } \\
\text { Empirical, cosine, } C \text { and Minnaert }\end{array}$ & Wu et al., 2008 & \\
\hline & Cosine, SCS, b and VECA & Gao and Zhang, 2009 & Variable empirical coefficient algorithm \\
\hline & C, modified Minnaert and Gamma & Richter et al., 2009 & \\
\hline & Simplified normalization & Cuo et al., 2010 & \\
\hline & Cosine, C, Minnaert, modified Minnaert and empiric-statistic correction & Hantson and Chuvieco, 2011 & \\
\hline & Cosine, C, smooth C, SCS+C, C-Huang Wei and slope matching & Singh et al., 2011 & \\
\hline & Modified C-correction & Veraverbeke et al., 2011 & \\
\hline & Three-factor+C & Zhang and Gao, 2011 & \\
\hline & Cosine, Minnaert, C, SCS, two stage topo normalization and slope matching & Zhang et al., 2011 & \\
\hline \multirow{13}{*}{$\begin{array}{l}\text { Int. or } \\
\text { comb. }\end{array}$} & Inverse technique + band ratios & Conese et al., 1993 & \\
\hline & ATCOR2 + DEM [ATCOR3] & Richter, 1997; Richter and Schäpfler, 2002; & \\
\hline & $6 \mathrm{~S}+\mathrm{DEM}$ & $\begin{array}{l}\text { Richter and Schapfler, } 2011 \\
\text { Sandmeier and Itten, } 1997\end{array}$ & \\
\hline & DOS + Minnaert, $\mathrm{C}$ and variation of $\mathrm{C}$ & Riaño et al., 2003 & \\
\hline & DOS + cosine and SCS & Vincini and Frazzi, 2003 & \\
\hline & ATCOR2 + Minnaert & Mitri and Gitas, 2004 & \\
\hline & LOWTRAN-7 + Minnaert & Gitas and Devereux, 2006 & \\
\hline & MODTRAN + SCS & Huang et al., 2008 & \\
\hline & $\mathrm{TF}+\mathrm{PBC}[\mathrm{IRC}]$ & Kobayashi and Sanga-Ngoie, 2008 & Integrated radiometric correction \\
\hline & DTA and $6 \mathrm{~S}+$ cosine and $\mathrm{C}$ & Vicente-Serrano et al., 2008 & Dark target approach \\
\hline & MODTRAN-4 + AMARTIS and SIERRA & Lenot et al., 2009 & $\begin{array}{l}\text { Advanced modeling of atmospheric radiative transfer for inhomogeneous } \\
\text { surfaces; Spectral reflectance image extraction from radiance with relief and } \\
\text { atmospheric correction }\end{array}$ \\
\hline & DOS + Minnaert and SCS & Gao and Zhang, 2009 & \\
\hline & Parameterized BRDF & Wen et al., 2009 & Bidirectional reflectance distribution function \\
\hline
\end{tabular}


Table 2. Equations and references of the two applied atmospheric corrections.

\begin{tabular}{llll}
\hline AC & Equation & (2) & Chavez, 1996 \\
\hline DOS & $L_{p, \lambda}=L_{s, \lambda}-L_{\text {min }}$ & (3) & $\begin{array}{l}\text { Kobayashi and Sanga-Ngoie, } \\
2008\end{array}$ \\
$L_{p, \lambda}=\frac{L_{s, \lambda}-L_{\min }}{0.5\left(1+T_{r, \lambda}\right) T_{r, \lambda} T_{w, \lambda}^{2}}$ & $=\exp \left[-\frac{P}{P_{0}} M \frac{1}{115.6406 \lambda^{4}-1.335 \lambda^{2}}\right]$ \\
& $T_{r}=\frac{1}{\cos \theta_{s}+0.15\left(93.885-\theta_{s}\right)^{-1.253}}$ \\
& $T_{w, \lambda}=\exp \left[-\frac{0.2385 a_{w} W M}{\left(1+20.07 a_{w} W M\right)^{0.45}}\right]$
\end{tabular}

Note: DOS is the dark object subtraction method and TF is the atmospheric correction based on transmittance functions. $L_{p, \lambda}$ (in $\mathrm{W} / \mathrm{m}^{2} \mathrm{sr} \mu \mathrm{m}$ ) is the path radiance of the image and $L_{s, \lambda}$ is the uncorrected radiance of the image. $L_{\min }$ represents the minimum radiance value of the image, calculated as the $1^{\text {th }}$ percentile. $T_{r, \lambda}$ is the Rayleigh scattering transmittance function, including sea-level atmospheric pressure $\left(P_{0}\right.$; in mbar), ambient atmospheric pressure $(P$; in mbar) and band wavelength $(\lambda) . M$ is the relative air mass and $\theta_{s}$ is the solar zenith angle (in degrees). $T_{w, \lambda}$ is the water-vapor transmittance function, calculated with the precipitable water vapor $(W$; in $\mathrm{cm})$, relative air mass $(M)$ and water-vapor absorption coefficients $\left(a_{w}\right)$. 
Table 3. Equations and references of the four applied topographic corrections.

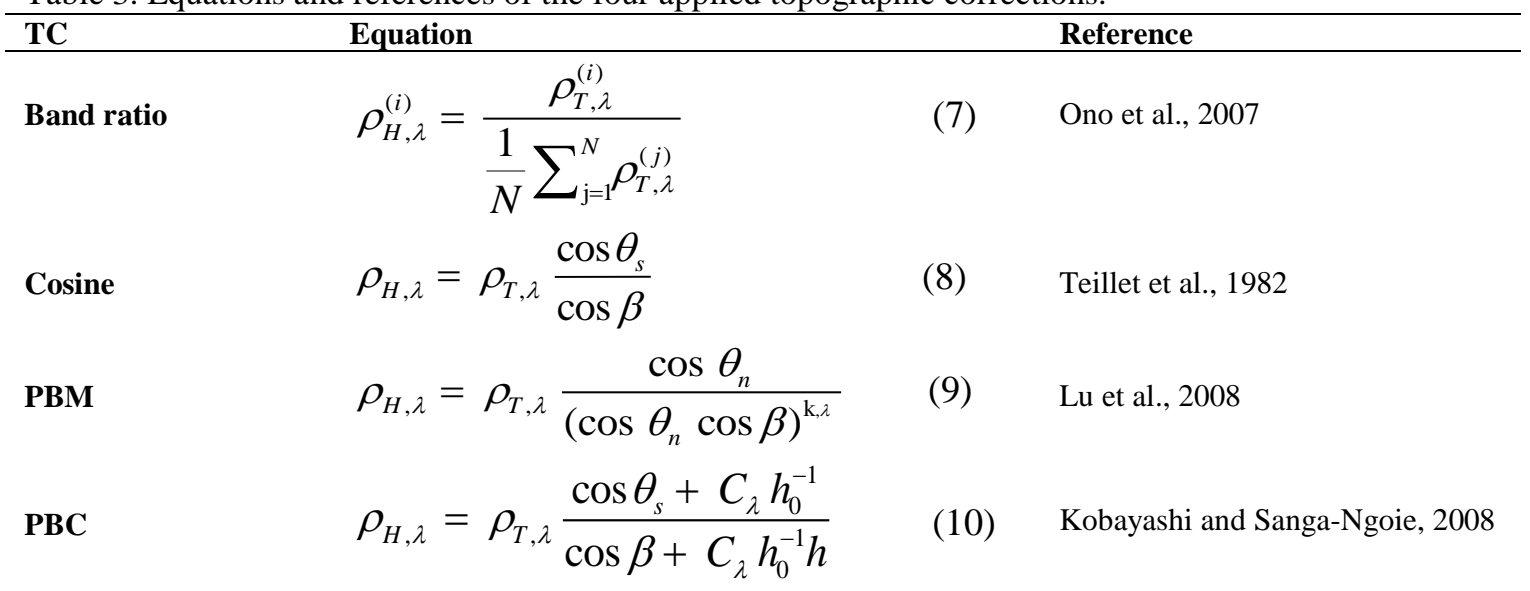

Note: PBM is the pixel-based Minnaert correction and PBC is the pixel-based C-correction. $\rho_{H, \lambda}$ (dimensionless or \%) stands for the normalized reflectance of a horizontal surface for a specific spectral band number $(N)$ and $\rho_{T, \lambda}$ for the observed reflectance on an inclined terrain. $\theta_{s}$ is the solar zenith angle and $\beta$ is the incident solar angle. $\theta_{n}$ is the slope angle of the terrain and $\mathrm{k}_{, \lambda}$ is the slope of the regression between $x=\log \left(\cos \theta_{n} \cos \beta\right)$ and $y=\log \left(\rho_{T, \lambda} \cos \theta_{n}\right)$. Parameter $C_{\lambda}$ is the quotient of intercept $\left(b_{\lambda}\right)$ and slope $\left(m_{\lambda}\right)$ of the regression line between $x$ and $y$. The $h$-factor represents a topographic parameter derived from the SRTM $\left(h=1-\theta_{n} / \pi\right)$ and the $h_{0}$-factor an empirical parameter derived from the regression line between reflectance and $\cos \beta\left(h_{0}=\left(\pi+2 \theta_{s}\right) / 2 \pi\right)$. 
Table 4. Difference in average reflectance values (\%) between illuminated and shaded forest slopes of band 4 for the 15 combined corrections and ATCOR3 (in parentheses). The asterisks indicate a significant t-test between all pairs of shaded and illuminated slope groups before and after correction at the significance level 0.05 .

\begin{tabular}{|l|c|c|c|c|c|}
\hline & No TC & Band ratio & Cosine & PBM & PBC \\
\hline No AC & 10.16 & 5.56 & -2.36 & 4.65 & $-1.91^{*}$ \\
\hline DOS & 9.86 & 5.12 & -2.34 & 5.04 & $-1.62^{*}$ \\
\hline TF & 8.54 & 5.83 & -1.56 & $4.14^{*}\left(3.73^{*}\right)$ & $-0.83^{*}$ \\
\hline
\end{tabular}


Table 5. CV values for each band, average $\mathrm{CV}$ and $\mathrm{CV}_{\text {difference }}$ values over all bands (dimensionless) of the 15 combined corrections and ATCOR3 (in parentheses) for the selected forest pixels.

\begin{tabular}{|l|l|c|c|c|c|c|c|c|c|}
\hline CV & & TM1 & TM2 & TM3 & TM4 & TM5 & TM7 & Average & Difference \\
\hline No AC & No TC & 45.66 & 54.16 & 71.46 & 33.58 & 41.21 & 40.98 & 47.84 & $/$ \\
& Band ratio & 42.44 & 57.74 & 75.51 & 30.32 & 45.49 & 42.08 & 48.93 & 1.09 \\
& Cosine & 44.68 & 54.32 & 67.82 & 24.81 & 40.97 & 39.05 & 45.27 & 2.57 \\
& PBM & 41.55 & 48.73 & 64.37 & 30.55 & 36.98 & 36.96 & 43.19 & 4.65 \\
& PBC & 41.51 & 46.56 & 62.71 & 30.14 & 35.09 & 37.60 & 42.27 & 5.57 \\
\hline DOS & No TC & 44.93 & 53.60 & 67.18 & 34.90 & 40.78 & 39.40 & 46.80 & 1.04 \\
& Band ratio & 41.71 & 51.68 & 65.84 & 31.03 & 37.31 & 37.83 & 44.23 & 3.61 \\
& Cosine & 43.69 & 52.57 & 67.76 & 30.79 & 37.98 & 38.00 & 45.13 & 2.71 \\
& PBM & 41.28 & 49.53 & 63.86 & 27.77 & 36.98 & 37.40 & 42.80 & 5.04 \\
& PBC & 40.62 & 49.80 & 60.66 & 26.62 & 34.82 & 37.13 & 41.61 & 6.23 \\
\hline TF & No TC & 43.80 & 52.85 & 65.86 & 33.18 & 40.26 & 39.98 & 45.99 & 1.85 \\
& Band ratio & 41.16 & 49.87 & 64.87 & 30.26 & 37.62 & 38.41 & 43.70 & 4.14 \\
& Cosine & 41.02 & 50.28 & 67.92 & 27.53 & 36.81 & 36.44 & 43.33 & 4.51 \\
& PBM & 40.05 & 46.58 & 63.53 & 23.45 & 33.55 & 30.84 & 39.67 & 8.17 \\
& & $(39.74)$ & $(46.89)$ & $(62.87)$ & $(23.16)$ & $(33.87)$ & $(29.61)$ & $(39.36)$ & $(8.48)$ \\
& PBC & 39.26 & 46.50 & 61.58 & 24.39 & 34.80 & 28.91 & 39.24 & 8.60 \\
\hline
\end{tabular}




\section{S. Vanonckelen et al.}

Table 6. Slope and $\mathrm{P}$ value of correlation analysis of the selected forest pixels in band 4 for the 15 combined corrections and ATCOR3 (in parentheses).

\begin{tabular}{|l|c|c|c|c|c|c|c|c|c|c|}
\hline & \multicolumn{2}{|c|}{ No TC } & \multicolumn{2}{c|}{ Band ratio } & \multicolumn{2}{c|}{ Cosine } & \multicolumn{2}{c|}{ PBM } & \multicolumn{2}{c|}{ PBC } \\
\hline & slope & $\mathrm{P}$ & slope & $\mathrm{P}$ & slope & $\mathrm{P}$ & slope & $\mathrm{P}$ & slope & P \\
\hline No AC & 16.3 & $<0.001$ & -3.6 & $<0.001$ & -10.7 & $<0.001$ & 3.0 & 0.312 & 2.9 & 0.326 \\
\hline DOS & 13.9 & $<0.001$ & -3.3 & $<0.001$ & -9.8 & $<0.001$ & 2.5 & 0.351 & 2.5 & 0.355 \\
\hline TF & 12.5 & $<0.001$ & -3.0 & $<0.001$ & -9.4 & $<0.001$ & 2.2 & 0.378 & 2.3 & 0.384 \\
& & & & & & & $(2.1)$ & $(0.386)$ & & \\
\hline
\end{tabular}




\section{International Journal of Remote Sensing}

Table 7. Slope and $\mathrm{P}$ value of correlation analysis of the stratified sample in band 4 over the entire image for the 15 combined corrections and ATCOR3 (in parentheses).

\begin{tabular}{|l|c|c|c|c|c|c|c|c|c|c|}
\hline & \multicolumn{2}{|c|}{ No TC } & \multicolumn{2}{c|}{ Band ratio } & \multicolumn{2}{c|}{ Cosine } & \multicolumn{2}{c|}{ PBM } & \multicolumn{2}{c|}{ PBC } \\
\hline & slope & $\mathrm{P}$ & slope & $\mathrm{P}$ & slope & $\mathrm{P}$ & slope & $\mathrm{P}$ & slope & P \\
\hline No AC & 14.6 & $<0.001$ & -2.5 & $<0.001$ & -9.3 & $<0.001$ & 2.1 & 0.365 & 2.3 & 0.386 \\
\hline DOS & 12.6 & $<0.001$ & -2.1 & 0.001 & -8.5 & $<0.001$ & 1.8 & 0.403 & 1.6 & 0.412 \\
\hline TF & 11.4 & $<0.001$ & -1.9 & 0.001 & -8.7 & $<0.001$ & 1.3 & 0.465 & 0.7 & 0.483 \\
& & & & & & & $(1.1)$ & $(0.474)$ & & \\
\hline
\end{tabular}




\section{S. Vanonckelen et al.}

Figure 1. SRTM from Romania and indication of the surrounding countries. The white-outlined rectangle delineates the study area, the solid white rectangle a zoom in the study area.

Figure 2. Average reflectance (\%) calculated in the forest class as a function of spectral band: (a) no AC or TC; (b) DOS without TC; (c) DOS with band ratio; (d) TF with cosine; (e) TF with PBM and (f) TF with PBC. The dashed line with square dots denotes the illuminated areas, the solid line with round dots the shaded areas. The whiskers represent the standard deviations.

Figure 3. True color composite images (RGB: band 3,2 and 1) of the zoom in the study area with a linear stretching: (a) no AC or TC; (b) DOS without TC; (c) DOS with band ratio; (d) TF with cosine; (e) TF with PBM and (f) TF with PBC. 